\title{
Environmental Health Officers and climate change adaptation in British Columbia
}

\author{
Laura McKelvey ${ }^{1}$, Helen Heacock ${ }^{2}$
}

${ }^{1}$ Lead Author, B. Tech Student, School of Health Sciences, British Columbia Institute of Technology, 3700 Willingdon Ave, Burnaby, BC V5G 3H2

${ }^{2}$ Supervisor, School of Health Sciences, British Columbia Institute of Technology, 3700 Willingdon Ave, Burnaby, BC V5G 3H2

\begin{abstract}
Background: The average annual temperatures in British Columbia have been steadily increasing in recent history and are expected to continue to rise. Climate change impacts have a significant effect on public health, and adaptation to these changes is necessary. Environmental health officers (EHOs) are in a position to deliver climate change adaptation programs in public health. The purpose of this study was to assess EHO perception of climate change adaption and identify knowledge or policy gaps.

Methods: A self-administered online survey created used Google Forms was distributed through e-mail and social media to EHOs in BC. The survey asked for demographics information, beliefs about climate change, adaption, and public health. Chi-square tests and descriptive statistics were used to analyze results.

Results: There was a significant association found between working in a mixed urban and rural environment and the incorporation of climate change adaptation into practice and the belief that climate change has impacted public health in BC. No association was found between years of experience and incorporation of adaptation.

Conclusion: While EHOs generally recognize the public health impacts of climate change, there are many barriers preventing EHO involvement in climate change adaptation.
\end{abstract}

Keywords: climate change adaptation, environmental health officers, EHOs, public health

\section{Introduction}

Accumulation of carbon dioxide

and greenhouse gas emissions has significantly impacted the global climate. There is an intimate relationship between human health and the environment, and as a result, the changing climate has brought new challenges to the field of public health. As the effects of climate change increase in severity globally, the effect on the health of British Columbians can already be observed and is expected to worsen over time.

In $\mathrm{BC}$, the average annual temperature has increased by $1.4^{\circ} \mathrm{C}$ since 1900 and it is predicted to increase by as much as $2.7^{\circ} \mathrm{C}$ by the year 2050 . (1) Temperature changes have already caused an increase in precipitation, glacial melt, and drought. (1) The variation in BC's geography presents further challenges.

The human health effects from climate change are becoming increasingly apparent. Climate change is known to influence heat-related morbidity and mortality, infectious disease, air pollution, allergens, food and water security, mental health, and injury. (2-7) Health effects of climate change tend to impact people of vulnerable socio-economic and health status more severely. (2) In BC, there is a 
pronounced gap in health status between rural northern communities and urban areas in the southwest, which is expected to worsen as climate change progresses and remote populations are not adequately equipped to adapt. (2)

While the health effects of climate change are fairly well understood, there is a lack of action to address and adapt to the changes in the environment that have already happened. There is no legislation in $\mathrm{BC}$ or Canada that ties climate change mitigation or adaptation with public health. However, the health effects of climate change are becoming very real in many $\mathrm{BC}$ communities and necessitating the involvement of health professionals to address it as a threat to public health. The purpose of this review is to explore how Environmental Health Officers (EHOs) or Public Health Inspectors (PHIs) could fit into climate change adaptation in $\mathrm{BC}$, and to identify knowledge and policy gaps.

\section{Literature Review Climate Change Effects in British Columbia}

Unseasonably higher winter temperatures have contributed to the Mountain Pine Beetle infestation, causing tree die-off and dramatic change to forests in central areas of the province. (3) The changes as a result of Mountain Pine Beetle infestation have increased the risk of wildfires, which subsequently affect air quality. (2) Sparser forests also lead to increased surface water yield and erosion. $(2,3)$ Greater amounts of sediment in water sources impacts quality and safety, as high water turbidity negatively affects the ability to disinfect water sources. Overloaded water treatment systems due to intense run-off or snowmelt have been associated with an increased incidence of gastrointestinal illness. (8)
Changes in the climate have altered the patterns of some pathogens, especially those with seasonality, such as Campylobacter, Cryptococcus gatti, and influenza. $(2,7)$ Cryptococcus gatti emerged as a human pathogen on Vancouver Island in 1999, and has since spread to colonize other areas of the Pacific Northwest due to favorable environmental conditions. (7) Extreme weather events and flooding, which are expected to increase in frequency and severity, are a factor in triggering waterborne illness outbreaks. (5) Changes in the distribution of diseases such as West Nile Virus and Lyme disease have also been attributed to climate change. (6)

Parts of Western Canada are expected to be more susceptible to drought as climate change progresses. (4) Drought tends to impact respiratory health, food and water security, and infectious disease. (4) Heat waves typically affect urban areas more severely due to the heat island effect and can result in severe health consequences, particularly for seniors, young children, and vulnerable socioeconomic groups. (2) EHOs/PHIs have a role in managing the health effects of environmental hazards, such as poor quality water supplies, air quality, and infectious disease control. Working closely with the environment puts EHOs/PHIs in a position where the effects of climate change are likely noticeable, and adaptation to climate change is necessary. EHOs/PHIs could deliver climate adaptation messages in a public health context, due to their understanding of the health effects of the environment, experience with the public, and working relationships with other agencies. 


\section{Perception of Climate Change as a Human Health Risk}

Assessing the public perception of climate change and the associated negative health effects is an important step in developing a public health initiative to address climate change and adaptation. Cardwell and Elliot (2013) conducted semi-structured interviews with residents of Southern Ontario to gauge public understanding of the human health risks of climate change. While $77 \%$ interviewees could identify environmental impacts of climate change, very few recognized the health and community effects. (9) Participants also responded that they "didn't know what to do" when it came to environmentally friendly behavior change.

(9) The lack of knowledge about the health effects of climate change and behavior change indicated the need for clear public health messages and engagement.

Similarly, a survey of residents of Canada, the United States, and Malta found that most respondents could not make a clear association between climate change and human health risk. (10) However, $67 \%$ of Canadian respondents indicated they believed that they were vulnerable to the effects of climate change. (10) Personal sense of risk could be utilized as a motivator for individual behavior change for climate change mitigation and adaptation. One review also identified the need for climate change risk communication messages to be tailored to specific at-risk groups to maximize effectiveness of education initiatives, since there appears to be a disconnect between public concern and action. (11)

The perception of climate change and health can also vary among public health professionals. In California, a group of public health officers were surveyed to determine their level of concern about the public health impacts of climate change. (12) While most felt that climate change posed a serious threat to health, the public health officers did not feel that they had sufficient resources or information to address it. (12) Budgetary limitations, coordination with other agencies, and lack of practical and actionable climate change information were identified as some of the barriers to address the need for public health interventions for climate change. (12)

In a survey of key informants at $\mathrm{BC}$ health authorities, the BC Healthy Communities Society found comparable perceptions and responses to climate change as found among the Californian public health officers. (13) Despite similar barriers to action, respondents suggested that public health should play a more considerable role in climate change. (13) Evidence based and regionally specific data, improved local partnerships, and provincial leadership were identified as opportunities to develop public health practice for climate change adaptation. (13)

Shifting Framework and Mainstreaming Although climate change has been identified as a human health concern, there has been resistance to creating new policies or policy instruments to tackle it. There has been a shift to "mainstreaming" climate change and health adaptation into existing processes and frameworks. (14) While a survey of public health officials in Ontario identified a framework shift as an opportunity to include health and climate change in policy, most respondents acknowledged a need for more research and assessment of regional vulnerability to the health effects of climate change. (14) Climate change adaptation could be incorporated into existing risk management practices in 
public health, which could reduce the resources required to develop new strategies.

Another survey of actors in Ontario's the public health sector found that health officials felt that climate change adaptation should be incorporated into existing public health programs, official community plans, and transportation plans. (15) They also discussed the need for collaborating between different levels of government and multidisciplinary partnerships to support the integration of climate change adaptation into existing public health initiatives. (15)

In the United Kingdom, climate change adaptation, risk assessment, and mitigation planning has been taken on by EHOs/PHIs $(16,17)$. All EHOs/PHIs interviewed incorporated climate change adaptation and communication into their work. (16) Many of the adaptation and sustainability efforts taken by EHOs/PHIs were framed as a cost saving measure for the future, rather than just for health protection. (16) In 2013, the UK National Adaptation Plan was published specifically for the health and social care sectors, which initiated public health involvement in climate change planning and adaptation. (17) Despite government involvement in climate change adaptation, a study of Directors of Public Health suggested that reframing adaptation would help overcome barriers and advance the issue further into policy. (17) They recommended shifting to frameworks of "community resilience", "sustainability", and "reducing inequalities" to engage other stakeholders and the public in climate change adaptation and make it a higher priority on the public health agenda. (17)

\section{Adaptation at Different Levels of Government}

There is a consensus that climate change adaptation requires involvement of all levels of government. With the signing of the Paris Agreement in 2016 by member nations of the United Nations Convention on Climate Change, adaptation has been put on the policy agenda of many countries. In a review of government documents from OECD member countries, three key governance dimensions for adaptation were determined: cross-sectoral collaboration, vertical collaboration, and nation adaptation planning. (18) However, a 'one size fits all' approach to adaptation is not appropriate, as most countries have different environmental and population challenges. (18)

In Canada, the feasibility of a top-down approach to adaptation planning is questionable due to jurisdictional structure. Health Canada and Public Health Agency of Canada have started the process of examining adaptation opportunities, but regional vulnerability assessments should be done as a first step to taking action. (19) A review of climate change adaptation in Canadian jurisdictions recommended regular meetings of representatives from all sectors involved in health adaptation for knowledge sharing and coordinating activities. (19) Continued research and development of adaptation guides for health authorities were also recommended as support for adaptation measures on a local level. (19) Another review found that the Canadian government did have the capacity for a top-down adaptation framework, but the challenges of the nation's geographical variety has resulted in hesitation by federal agencies. (20) The lack of federal leadership has created a 'mosaic' of response, which has lead to 
disjointed action by provincial and local government. An absence of cohesion, however, has allowed health authorities to develop climate change adaptation as needed in their own communities. The bottom-up approach could be the most feasible option for adaptation in $\mathrm{BC}$, as the needs of communities across the province are considerably different.

\section{Barriers to Adaptation}

The major deterrent for the public health sector's involvement in climate change adaptation is the multitude of barriers preventing research, planning, and action. Among health department directors in the United States, there was attitudinal polarization on climate change over time, and some even doubted the threat of climate change. (21) They also noted a lack of readiness to adapt, particularly due to budgetary constraints and the shortage of practical information about climate change adaptation. (21) Those attitudes about the barriers to climate change adaptation were consistent in most of the literature on public health and climate change adaptation. The strain on resources, lack of research, regional inequalities, and the need for stakeholder buy-in would likely be barriers to $\mathrm{EHO} / \mathrm{PHI}$ involvement in adaptation. $(2,13)$ Resource limitations in regional health authorities would probably be the largest barrier for climate change adaptation. EHOs/PHIs are already overextended in their work in many cases, and climate change adaptation may be considered low priority, as it is a hazard over the long-term.

\section{Research, Policy, and Knowledge Gaps}

Nearly all of the studies included in this review identified the limited availability of research and practical knowledge about climate change adaptation as a significant issue. There is very little evidence-based research done on climate change adaptation and the health effects of climate change in Canada. The need for knowledge sharing among public health professionals was also identified, which could assist in incorporating adaptation into practice and educating the public. $(2,12,13)$ Currently, the climate change strategy and legislation in BC only targets industry and greenhouse gas emissions. (1) There is an opportunity for health adaptation to be included in provincial planning and policy, which could aid health authorities in developing their own adaptation and mitigation strategies.

\section{Conclusions}

Climate change is a reality in $\mathrm{BC}$ and there is extensive evidence of the health effects of climate change, however, there is little done to address it and adapt in the public health sector. Due to $\mathrm{EHO} / \mathrm{PHI}$ involvement in health hazard abatement and the connection between human health and the environment, EHOs/PHIs are in an excellent position to incorporate adaptation into practice and education. Mainstreaming and integrating adaptation into existing policy could help overcome some barriers to adaptation and improve perceptions of the public and governmental agencies. While climate change mitigation is a popular topic in $\mathrm{BC}$, climate change adaptation is rarely a priority, particularly in the public health sector. Developing ways to address the potentially irreversible environmental changes $\mathrm{BC}$ is already experiencing is going to be necessary to face emerging public health challenges resulting from climate change. The purpose of this study was to examine the perception of climate change adaptation among EHOs/PHIs in $\mathrm{BC}$, as well as if and how EHOs/PHIs incorporate climate change adaptation into practice. 


\section{Methods}

\section{Materials Used}

Data for this study was collected through a self-administered web-based survey. Participation in the study required access to the Internet and Google Docs. The survey was created using Google Forms, a free online survey program offered by Google. Survey results were automatically compiled and recorded to Google Spreadsheet, which was then exported to Microsoft Excel. (22) The results were analyzed using SPSS statistical software and VassarStats. (2224) A cover letter and consent form were provided to prospective participants to state the purpose and obtain consent prior to doing the survey.

\section{Description of Standard Methods}

The self-administered online survey was distributed to practicing Environmental Health Officers (EHOs) in British Columbia through a link to the Google Forms survey. Participants were reached by e-mail distributed to Canadian Institute of Public Health Inspectors (CIPHI) members in $\mathrm{BC}$ and through the BCIT Environmental Health group on Facebook. The survey consisted of closedended questions to ascertain demographics of participants, such as years of experience, setting and organization of employment, and whether they were currently practicing as an EHO. Questions regarding perception of climate change as a health issue, incorporation of climate change adaptation in practice, $\mathrm{EHO}$ involvement in climate change response, and access to information were included in the survey. Some questions included an "other" option in which participants are given the opportunity to write in their own response if applicable. At the end of the survey, participants were given the option to submit their email to be entered into a prize draw.
The data collecting features of Google Forms are automated, and allow results to be downloaded to Microsoft Excel. (25) Google Forms gives real-time information about number of responses and quality of responses, in addition to preliminary breakdown of results using graphics. The data downloaded to Microsoft Excel was exported to SPSS statistical software for analysis. Chisquare tests were used to compare background information and demographics responses with answers given to the survey questions regarding perceptions and work practices.

\section{Inclusion and Exclusion Criteria}

People working as EHOs in BC at the time of the study were invited to participate. Other professionals in the environmental health field such as those working in private industries and program instructors were also invited to complete the survey. Those who did not authorize consent to participate or did not fit the inclusion criteria were excluded.

\section{Ethical Considerations}

This research was performed on human participants, and as such, ethical concerns needed to be addressed. (26) A cover letter and consent form explaining the purpose of the study and reassuring participant confidentiality was attached to the survey. Informed consent was obtained from participants by acceptance of the consent form at the beginning of the survey. Participation in the study did not increase risk above that of daily living for respondents, and participants benefited from their contribution to scientific knowledge. The survey was submitted and reviewed for ethics approval by the course instructors prior to dissemination. 


\section{Statistical Analysis \\ Description of Data}

The data collected in this survey was a combination of binary and multichotomous nominal data and ordinal data. The first section of the questionnaire was used to collect nominal and ordinal data regarding background information. The second section included a series of questions to collect multichotomous and binary nominal and ordinal data, with some opportunity for participants to write in their own answer as "other". There was one question included that collected qualitative data in the form of a written answer to get a better understanding of how EHOs perceive the health effects of climate change and adaptation to climate change.

\section{Statistical Package Used}

The statistical software used

for analysis was SPSS GradPack 24.0. Results compiled by Google Forms were downloaded to Microsoft Excel to generate preliminary descriptive statistics. Chi-square tests in SPSS were used to determine association between EHO demographics, and Fisher's exact tests were performed using VassarStats. (24)

\section{Results}

\section{Descriptive Statistics}

In total, thirty-six individuals responded to the survey and fit the inclusion criteria, including currently employed EHOs $(91.7 \%, \mathrm{n}=33)$ and those not currently working as EHOs $(8.3 \%$, $\mathrm{n}=3$ ). Respondents were initially asked questions to determine demographics, including health authority of employment, position title, highest level of education, and work setting (Table 1). Participants were also asked for the number of years of experience as an $\mathrm{EHO}$, which were condensed into two groups: 10 years or less $(55.6 \%, \mathrm{n}=20)$ and more than 10 years of experience $(44.4 \%, \mathrm{n}=16)$.

Table 1: Summary of demographics

\begin{tabular}{|l|l|}
\hline \multicolumn{2}{|l|}{ Health Authority of employment } \\
\hline Interior Health & $47.1 \%(16)$ \\
\hline $\begin{array}{l}\text { Vancouver Coastal } \\
\text { Health }\end{array}$ & $17.6 \%(6)$ \\
\hline First Nations Health & $11.8 \%(4)$ \\
\hline Fraser Health & $8.8 \%(3)$ \\
\hline Northern Health & $8.8 \%(3)$ \\
\hline Vancouver Island Health & $5.9 \%(2)$ \\
\hline Position title & \multicolumn{2}{|l|}{} \\
\hline EHO - Generalist & $58.8 \%(20)$ \\
\hline EHO - Specialist & $20.6 \%(7)$ \\
\hline Supervisor & $11.8 \%(4)$ \\
\hline Other & $8.8 \%(3)$ \\
\hline Years of experience & \multicolumn{2}{|l|}{} \\
\hline 10 years or less & $55.6 \%(20)$ \\
\hline$>10$ years & $44.4 \%(16)$ \\
\hline Work setting & $55.6 \%(20)$ \\
\hline Mix of urban/rural & $22.2 \%(8)$ \\
\hline Urban & $22.2 \%(8)$ \\
\hline Rural & $75.0 \%(27)$ \\
\hline Highest level of education \\
\hline Bachelor's degree & $11.1 \%(4)$ \\
\hline Master's degree & $11.1 \%(4)$ \\
\hline Diploma/certificate & $2.8 \%(1)$ \\
\hline Other &
\end{tabular}

The second part of the survey consisted of questions regarding climate change and climate change adaptation. When participants were asked if they thought climate change impacted human health, 75\% $(\mathrm{n}=27)$ answered 'very much so', and $25 \%(\mathrm{n}=9)$ responded 'to some degree'. 
Fig. 1: Current and future health effects due to climate change in $\mathrm{BC}$ (opinion)

\section{Current health impact}

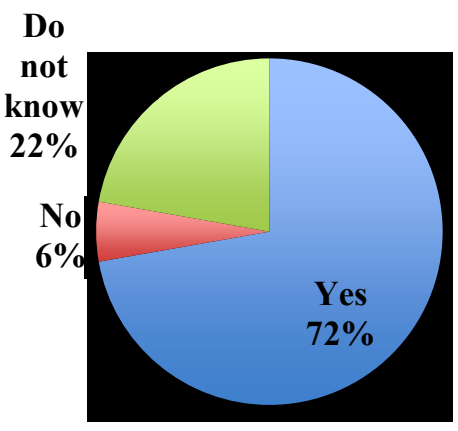

Future health impact

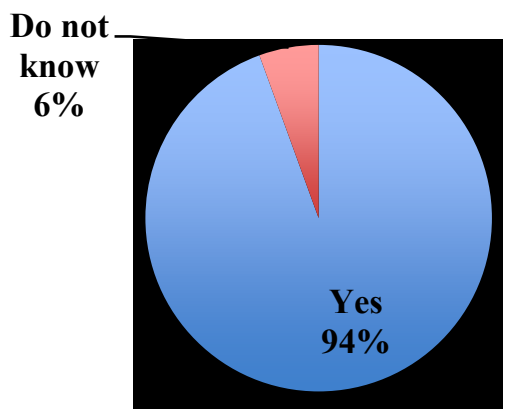

Fig. 2: Greatest risks to public health related to climate change

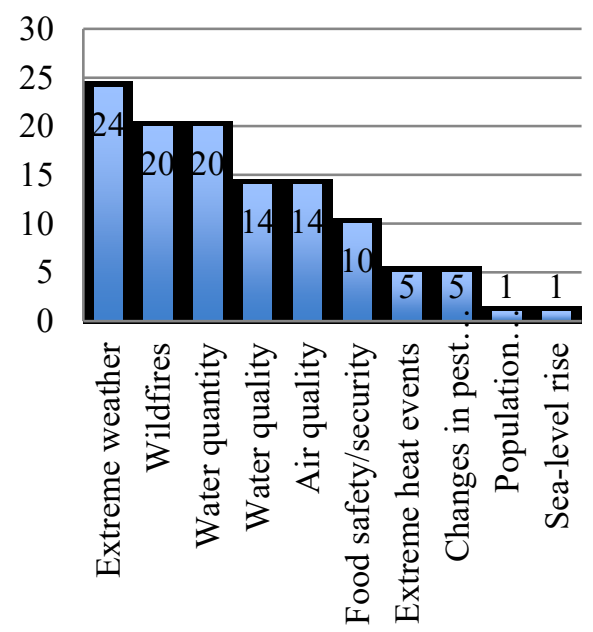

When asked if their health authority had a climate change adaptation strategy or plan, $62.9 \%(\mathrm{n}=22)$ responded that they did not know, while $28.6 \%(\mathrm{n}=10)$ responded 'no' and $8.6 \%(\mathrm{n}=3)$ did have plan. The majority of individuals incorporated adaptation into their work $(63.9 \%, n=23)$ and $30.6 \%(n=11)$ did not. The vast majority $(91.7 \%, n=33)$ thought that climate change adaptation should be incorporated somehow into EHO education, and the remainder was unsure. Most also believed that EHOs should be involved with climate change adaptation or mitigation $(77.1 \%, n=27)$, and $20 \%(n=7)$ had no opinion or did not know, while one respondent (2.9\%) answered 'no'.

Fig. 3: Areas in which climate change was most often considered

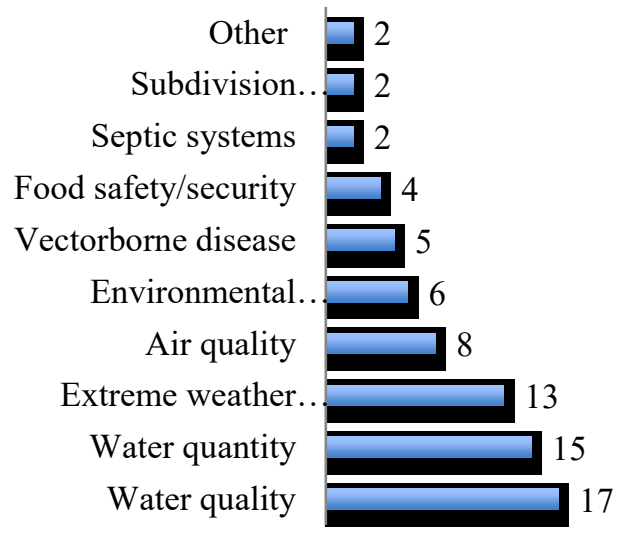

Fig. 4: Barriers to EHO involvement in climate change adaptation/mitigation

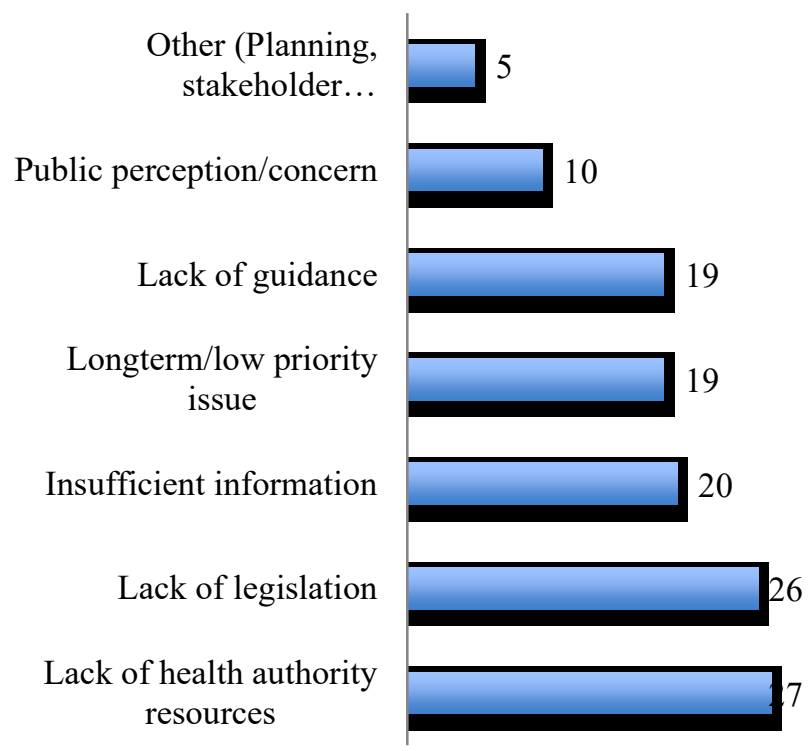




\section{Inferential Statistics}

Data collected was analyzed and interpreted using Chi square tests to compare demographic factors to answers about climate change adaptation. The chi square test is a method of interpreting the association between nominal and ordinal data. (27) In cases where the assumptions in the Chi square tests were violated, Fisher's exact tests were used, which are better suited to smaller sample sizes. (28) For the purposes of analysis, years of experience was collapsed into two categories: 10 years or less, and greater than 10 years of experience. In addition, two 'do not know' responses for incorporation into practice were not included and answers of 'do not know' $(n=8)$ and 'no' $(n=2)$ were combined into one category in response to the opinion that climate change has already impacted public health in BC.

Table 2: Summary of inferential statistics results

\begin{tabular}{|c|c|c|c|}
\hline $\mathrm{H}_{\mathrm{O}}$ and $\mathrm{H}_{\mathrm{A}}$ & Test Used & Result & Conclusion \\
\hline $\begin{array}{l}\mathrm{H}_{\mathrm{O}} \text { : There is no association } \\
\text { between work setting and } \\
\text { incorporation of climate } \\
\text { change adaptation into practice } \\
\mathrm{H}_{\mathrm{A}} \text { : There is an association } \\
\text { between work setting and } \\
\text { incorporation of climate } \\
\text { change adaptation into practice }\end{array}$ & $\begin{array}{l}\text { Chi-square test } \\
\text { (Fisher's exact } \\
\text { test) }\end{array}$ & $P=0.018$ & $\begin{array}{l}\text { Reject } \mathrm{H}_{\mathrm{O}} \text { and } \\
\text { conclude there is an } \\
\text { association between } \\
\text { work setting and } \\
\text { incorporation of } \\
\text { climate change } \\
\text { adaptation into } \\
\text { practice. EHOs in } \\
\text { mixed urban/rural } \\
\text { setting used } \\
\text { adaptation more. }\end{array}$ \\
\hline $\begin{array}{l}\mathrm{H}_{\mathrm{O}} \text { : There is no association } \\
\text { between work setting and } \\
\text { belief that climate change has } \\
\text { impacted public health in } \mathrm{BC} \\
\mathrm{H}_{\mathrm{A}} \text { : There is an association } \\
\text { between work setting and } \\
\text { belief that climate change has } \\
\text { impacted public health in } \mathrm{BC}\end{array}$ & $\begin{array}{l}\text { Chi-square test } \\
\text { (Fisher's exact } \\
\text { test) }\end{array}$ & $\mathrm{P}=0.017$ & $\begin{array}{l}\text { Reject } \mathrm{H}_{\mathrm{O}} \text { and } \\
\text { conclude there is an } \\
\text { association between } \\
\text { work setting and } \\
\text { belief that climate } \\
\text { change has impacted } \\
\text { public health in BC. } \\
\text { More EHOs in mixed } \\
\text { urban/rural settings } \\
\text { believed that climate } \\
\text { change has impacted } \\
\text { health. }\end{array}$ \\
\hline $\begin{array}{l}\mathrm{H}_{\mathrm{O}} \text { : There is no association } \\
\text { between years of experience } \\
\text { and incorporation of climate } \\
\text { change adaptation into practice } \\
\mathrm{H}_{\mathrm{A}} \text { : There is an association } \\
\text { between years of experience } \\
\text { and incorporation of climate } \\
\text { change adaptation into practice }\end{array}$ & Chi-square test & $\mathrm{P}=0.897$ & $\begin{array}{l}\text { Do not reject } \mathrm{H}_{\mathrm{O}} \text { and } \\
\text { conclude there is no } \\
\text { association between } \\
\text { years of experience } \\
\text { and climate change } \\
\text { adaptation in practice }\end{array}$ \\
\hline
\end{tabular}


Analysis of the data concluded that there were statistically significant associations between work setting and incorporation of climate change adaptation and belief that climate change has impacted health in $\mathrm{BC}$ communities. There was also no association found between years of experience as an EHO and incorporation of adaptation into practice.

The statistical analysis may be subject to error, particularly type I and type II error. Type I error is the incorrect rejection of the null hypothesis, which may be reduced by lowering the acceptable $\alpha$ value. (29) For the first two statistical tests, if the acceptable $\alpha$ value was reduced to 0.01 , the $\mathrm{P}$ value would no longer be significant and $\mathrm{H}_{\mathrm{O}}$ would not be rejected.

\section{Discussion}

The objective of this study was to determine how EHOs could fit climate change adaptation into their health protection role. The results indicated that EHOs in BC are already incorporating climate change adaptation into their practice and are generally aware of the health impacts of climate change. When looking at work setting, there was an association between working in a mixed urban and rural environment and the incorporation of climate change adaptation into their work $(\mathrm{P}=0.018)$. There was also an association found between working in a mixed environment and belief that climate change is already impacting the health of communities in $\mathrm{BC}(\mathrm{P}=0.017)$. The association may be attributed to the exposure these EHOs would have to varied environments that could more easily highlight the impacts of climate change.

While it could be expected that more experience in the field may be associated with incorporation of adaptation in practice due to observation of environmental changes, there was no association found between years of experience and consideration of climate change $(\mathrm{P}=0.897)$. This may be due to the high level of awareness of the link between health and climate change among the EHOs surveyed or differences in job duties or personal opinions. The majority of EHOs acknowledged that climate change had a very close connection with human health (75\%), which is consistent with previous studies of public health professionals and much higher than surveys of the general public. $(9,10,12,13)$

The top three risks to public health as a result of climate change identified by the EHOs included in this study were extreme weather events, wildfires, and water quantity. These effects are among the most discussed in climate change literature, and a major concern in BC, especially with the change in forest landscape due to Mountain Pine Beetle infestations and rising average temperature. (1-3) The impact on forests will also affect surface water yield, making water availability and safety a concern for many communities. $(2,8)$ Managing the health effects of extreme weather and wildfires is already a part of EHO responsibilities, but the frequency of such events are likely to increase in the future.

Similar to the results of a survey of key $\mathrm{BC}$ health authority actors, most EHOs did not know whether their health authority had a climate change adaptation or mitigation plan. (13) This could be attributed to EHOs limited role in long-term health protection and planning, however, most (77.1\%) believed that EHOs should play a role. Changing the role of the EHO to address long-term health issues like climate change would necessitate a major shift in how health hazards are defined and addressed, which is starting to happen with the development of healthy built environment teams. However, such a shift could take the focus away from preventing and mitigating immediate health hazards and would require many barriers to be eliminated.

The barriers to climate change adaptation identified by the EHOs in this study are consistent with the results of several other studies of public health professionals. The results of this study and studies of public health 
professionals in the United States and Canada found that public health involvement in adaptation is prevented due to budgetary constraints, lack of legislation, insufficient research and actionable information, and the chronic nature of climate change impacts. (1214,21) These barriers may make it challenging and unrealistic for district EHOs to address the health impacts of climate change currently. However, planning and redefining the role of the EHO as the UK has done, could help to overcome the barriers faced by health authorities and EHOs in BC. $(16,17)$

\section{Limitations}

The size and demographics of the sample population included in this study were major limitations. Only thirty-six individuals participated in the survey, which represented approximately $29 \%$ of the 125 regular members of the CIPHI BC Branch at the time of the study. (30) The geographic distribution of EHOs that participated in the study was not a reflection of the true distribution of EHOs in BC. Nearly half (47.1\%) of respondents were employed with the Interior Health Authority, with very little representation from more urban areas, such as Fraser Health Authority or Vancouver Coastal Health Authority. Opinions and practices among EHOs may vary across the province, and as such, may not have been fully captured in this study. Internal validity may have been increased by ensuring that all EHOs in $\mathrm{BC}$ received the email survey, in addition to email reminders, as opposed to only members of CIPHI. This likely would have resulted in a more accurate representation of EHOs in the province.

The short time period in which this study was performed likely limited participation rates and magnitude of the research. Having the survey accessible for a longer than two weeks would have allowed for more opportunities for reminders and participation for EHOs not available during the initial distribution. More time may have allowed for the survey to be expanded to EHOs across Canada, which would have also improved external validity of the results.

\section{Knowledge Translation}

Based on the results of this study, EHOs generally acknowledge the health effects of climate change and the potential impact on many areas of environmental health. However, there were several opportunities identified for knowledge translation. Health authorities should consider developing plans for climate change adaptation, which may include guidance documents and information specifically for EHOs managing those issues in the field. Maintaining communication between health authorities and EHOs about climate change issues may help alleviate uncertainty about the subject and possibly create professional development opportunities.

While research into the impacts of climate change is ongoing, incorporation of public health into climate change legislation or policy is another avenue that could be considered. Having legal jurisdiction and mandate is an important aspect of environmental health work, so incorporation of public health into future climate change legislation would be the most effective way to facilitate EHO involvement. Incorporation of climate change adaptation into existing frameworks for initiatives for healthy built environments and reducing health inequities may also be option for mainstreaming into current public health agendas. (17)

\section{Future Research}

For a better understanding of the role of EHOs in climate change in $\mathrm{BC}$ or across Canada, future studies could be undertaken to determine:

- Whether there are differences in perceptions of climate change among EHOs in different provinces across Canada. 
- EHO knowledge of current climate change policy and legislation.

- Public knowledge of climate change adaptation.

\section{Conclusions}

The results of this survey indicated that EHOs in $\mathrm{BC}$ are well aware of climate change and it's impacts on public health. Several areas of importance for EHOs were identified in regards to climate change adaptation, including water quality, water availability, extreme weather events, and air quality. Statistical analysis of results revealed that there were associations between working in mixed urban and rural environments and incorporation of adaptation into practice and belief that climate change has impacted public health. The results also showed that years of experience in the field did not influence whether an EHO considers climate change and adaptation in their work.

This study confirmed several barriers to EHO involvement in climate change adaptation that have been identified in past research, including budgetary constraints, insufficient guidance, and access to information. $(12,13,21)$ As research and practical knowledge continues to be gathered about the health effects of climate change, some barriers to adaptation may be overcome. Incorporating public health perspectives into climate change planning and legislation would ease the transition for EHOs and health authorities to contribute to climate change adaptation. EHOs are also becoming more involved with healthy built environments, and working climate change adaptation into that may be part of a bottom-up approach to adaptation. As climate change continues to be a concern for both the environment and public health, there needs to be greater partnership between different sectors of governments and health authorities to address the lack of planning, research, support, and guidance that are current barriers for adaptation. While higher-level changes are needed to facilitate EHO involvement in climate change adaptation, this study provides one step towards the necessary planning and action to address the changes to our environment and community health as the impacts of climate change intensify.

\section{Acknowledgements}

The authors thank the British Columbia Institute of Technology Environmental Health department for supporting their research. Special thanks also goes to the CIPHI BC Branch and the EHOs who participated in this study.

\section{Competing Interest}

The authors declare they have no competing interest.

\section{References}

1. Province of British Columbia. Climate Leadership Plan [Internet]. 2016. Available from: https://climate.gov.bc.ca/wpcontent/uploads/sites/13/2016/06/4030_CL P_Booklet_web.pdf

2. Ostry A, Ogborn M, Bassil KL, Takaro TK, Allen DM. Climate Change and Health in British Columbia: Projected Impacts and a Proposed Agenda for Adaptation Research and Policy. Int J Environ Res Public Health. 2010 Mar;7(3):1018-35.

3. Embrey S, Remais JV, Hess J. Climate change and ecosystem disruption: the health impacts of the North American Rocky Mountain pine beetle infestation. Am J Public Health. 2012 May;102(5):818-27.

4. Yusa A, Berry P, Cheng JJ, Ogden N, Bonsal B, Stewart R, et al. Climate Change, Drought and Human Health in Canada. Int J Environ Res Public Health. 2015 Jul;12(7):8359-412. 
5. Charron D, Thomas M, Waltner-Toews D, Aramini J, Edge T, Kent R, et al.

Vulnerability of waterborne diseases to climate change in Canada: a review. J Toxicol Environ Health A. 2004 Nov 22;67(20-22):1667-77.

6. Greer A, Ng V, Fisman D. Climate change and infectious diseases in North America: the road ahead. CMAJ Can Med Assoc J J Assoc Medicale Can. 2008 Mar 11;178(6):715-22.

7. MacDougall L, Kidd SE, Galanis E, Mak S, Leslie MJ, Cieslak PR, et al. Spread of Cryptococcus gattii in British Columbia, Canada, and Detection in the Pacific Northwest, USA. Emerg Infect Dis. 2007 Jan;13(1):42-50.

8. Galway LP, Allen DM, Parkes MW, Li L, Takaro TK. Hydroclimatic variables and acute gastro-intestinal illness in British Columbia, Canada: A time series analysis. Water Resour Res. 2015 Feb 1;51(2):88595.

9. Cardwell FS, Elliott SJ. Making the links: do we connect climate change with health? A qualitative case study from Canada. BMC Public Health. 2013;13:208.

10. Akerlof K, DeBono R, Berry P, Leiserowitz A, Roser-Renouf C, Clarke KL, et al. Public Perceptions of Climate Change as a Human Health Risk: Surveys of the United States, Canada and Malta. Int J Environ Res Public Health. 2010 Jun 14;7(6):2559-606.

11. Berry P, Clarke K-L, Pajot M, Hutton D. Risk Perception, Health Communication, and Adaptation to the Health Impacts of Climate Change in Canada. In: Ford JD, Berrang-Ford L, editors. Climate Change Adaptation in Developed Nations: From Theory to Practice. 1st ed. Springer
Netherlands; 2011. p. 205-19. (Advances in Global Change Research).

12. Bedsworth L. Preparing for Climate Change: A Perspective from Local Public Health Officers in California. Environ Health Perspect. 2009 Apr;117(4):617-23.

13. Barter S, Klein K. Health Authority Perceptions and Capactiy for Action: Health Impacts of Climate Change in BC [Internet]. 2013 [cited 2016 Oct 10]. Available from: http://bchealthycommunities.ca/res/downlo ad.php?id=900

14. Clarke K-L, Berry P. From theory to practice: a Canadian case study of the utility of climate change adaptation frameworks to address health impacts. Int $\mathbf{J}$ Public Health. 2012 Feb;57(1):167-74.

15. Paterson JA, Ford JD, Ford LB, Lesnikowski A, Berry P, Henderson J, et al. Adaptation to climate change in the Ontario public health sector. BMC Public Health. 2012;12:452.

16. Ratnapradipa D. 2012 NEHA/UL sabbatical report: vulnerability to potential impacts of climate change: adaptation and risk communication strategies for environmental health practitioners in the United Kingdom. J Environ Health. 2014 Apr;76(8):28-33.

17. Negev M, Kovats RS. Climate change adaptation in the reorganized UK public health system: a view from local government. Public Health. 2016 May;134:102-4.

18. Austin SE, Biesbroek R, Berrang-Ford L, Ford JD, Parker S, Fleury MD. Public Health Adaptation to Climate Change in OECD Countries. Int J Environ Res Public Health [Internet]. 2016 Sep [cited 2016 
Oct 11];13(9). Available from:

http://www.ncbi.nlm.nih.gov/pmc/articles/

PMC5036722/

19. Austin SE, Ford JD, Berrang-Ford L, Araos M, Parker S, Fleury MD. Public Health Adaptation to Climate Change in Canadian Jurisdictions. Int J Environ Res Public Health. 2015 Jan 12;12(1):623-51.

20. Dickinson T, Burnton I. Adaption to Climate Change in Canada: A Multi-level Mosaic. In: Ford JD, Berrang-Ford L, editors. Climate Change Adaptation in Developed Nations: From Theory to Practice. 1st ed. Springer Netherlands; 2011. p. 103-17. (Advances in Global Change Research).

21. Roser-Renouf C, Maibach EW, Li J. Adapting to the Changing Climate: An Assessment of Local Health Department Preparations for Climate Change-Related Health Threats, 2008-2012. PloS One. 2016;11(3):e0151558.

22. Microsoft Excel. Microsoft Corporation; 2010.

23. SPSS Statistics GradPack [Internet]. IBM; 2015. Available from: www.ibm.com

24. VassarStats: Statistical Computation Web Site [Internet]. [cited 2017 Feb 17]. Available from: http://vassarstats.net/
25. Google. Google Forms [Internet]. 2016 [cited 2016 Nov 19]. Available from: https://www.google.ca/forms/about/

26. Heacock H. ENVH 8400 Module 4 Ethical Issues in Research [Internet]. 2016 [cited 2016 Nov 12]. Available from: https://learn.bcit.ca/d21/le/content/330344/ viewContent/2011291/View

27. Schumacker R, Tomek S. Chi-Square Test. In: Understanding Statistics Using R [Internet]. Springer New York; 2013 [cited 2016 Nov 19]. p. 169-75. Available from: http://link.springer.com/chapter/10.1007/9 78-1-4614-6227-9_8

28. Statistics Canada. Survey Methods and Practices [Internet]. Minister of Industry; [cited 2016 Nov 19]. Available from: http://www.statcan.gc.ca/pub/12-587-x/12587-x2003001-eng.pdf

29. Heacock H. ENVH 8400 Powerpoint lecture slides. 2016; British Columbia Institute of Technology.

30. CIPHI. British Columbia Branch Regular Members [Internet]. 2016 [cited 2017 Apr 17]. Available from: http://www.ciphi.ca/mem-pdf/bc-reg.pdf 